\title{
Effects of trimetazidine on nerve regeneration in a rat sciatic nerve injury model
}

\author{
Karahan $\mathrm{G}^{1}$, Kaya $\mathrm{H}^{2}$, Erdogan $\mathrm{MA}^{3}$, Yigitturk $\mathrm{G}^{4}$, Gokyayla $\mathrm{E}^{5}$, Erbas $\mathrm{O}^{6}$ \\ Bozyaka Education and Research Hospital, Orthopedics And Traumatology Department, Izmir, Turkey. \\ dr.gokhan.karahan@gmail.com
}

\section{ABSTRACT}

AIM: The aim of this study was to evaluate the efficacy of trimetazidine(TMZ) after end-to-end repair in a peripheral nerve injury model.

METHOD: We performed end-to-end primary repair of sciatic nerves in rats and showed TMZ's regenerative effect. For this objective 30 male Sprague Dawley albino rats were used. Surgery+water group, rats were assigned to a placebo group and were given water by oral gavage. Surgery+TMZ group, rats were given trimetazidine by oral gavage. All medications were given for 12 weeks. Motor function test was performed. Afterwards, electromyography (EMG) recording was done. Finally, blood samples were taken, the animals were euthanized andsciatic nerve was removed.

RESULTS: The amplitudes of compound muscle action potential (CMAP) increased significantly in the Surgery+TMZ group when compared with the group that have been given Surgery+Water. Nerve growth factor (NGF) immunoexpression in the Schwann cell was significantly increased in the Surgery+TMZ group compared with the Surgery+Water group. Moreover, fibrosis score was reduced in the Surgery+TMZ group compared to the Surgery+Water group.

CONCLUSIONS: In conclusion, we demonstrated the superiority of TMZ on nerve healing in our experimental study which was evaluated with comparative groups (Tab. 3, Fig. 2, Ref. 31). Text in PDF www.elis.sk. KEYS WORDS: trimetazidine, nerve injury, primary repair, nerve regeneration.

\section{Introduction}

Peripheral nerve injuries mostly occur via mechanical traumas (1). Gold standard treatment method for post-traumatic loss of nerve integrity is primary end-to-end repair (2). Despite all studies about nerve regeneration after nerve repair, results are still not satisfactory. The reason for the complete recovery after nerve repair is independent of surgical technique, because the peripheral nerve cell has a complex structure (3). Many studies, effects of mechanical factors like surgical tecniques and suture materials on nerve healing were investigated; however now we know that axonal regeneration is dependent on lots of unknown factors beside mechanical factors (4). For nerve regeneration, an appropriate environment and release of several biochemical mediators

${ }^{1}$ Bozyaka Education and Research Hospital, Orthopedics and Traumatology Department, Izmir, Turkey, ${ }^{2}$ Ege Universty Faculty of Medicine Orthopedics and Traumatology Department, Izmir, Turkey, ${ }^{3}$ Izmir Katip Celebi University Faculty of Medicine Department of Physiology, Izmir, Turkey, ${ }^{4}$ Mugla University Faculty of Medicine Histology and Embryology, Mugla, Turkey, ${ }^{5}$ Ege Universty Faculty of Medicine, Izmir, Turkey, and ${ }^{6}$ Istanbul Bilim University Faculty of Medicine Department of Physiology, Istanbul, Turkey

Address for correspondence: G. Karahan, Bozyaka Education and Research Hospital, Orthopedics and Traumatology Department, Karabaglar 35000, Izmir, Turkey

Phone: +905064616366 are required. After direct mechanical nerve trauma, microvascular structures also get damaged with neural tissue. Edema and thrombosis which occur secondary to endothelial damage disrupt microcirculation. Free oxygen radicals are released in trauma area after neutrophil and macrophage infiltration. Microcirculation disorder and decrease of anti-oxidant enzymes enable the removal of free oxygen radicals. This situation delays the development of optimal environment for nerve healing process $(5,6)$. Critical role in this ischemia and reperfusion process is assumed by mitochondria (7). Trimetazidine (TMZ) specifically inhibits 3-ketoacyl coenzyme A thiolase (3-KAT) which is the last enzyme of fatty acid oxidation pathway. This causes a decrease in fatty acid oxidation and an increase in glucose oxidation. TMZ optimizes mitochondirial oxygen requirements, inhibits reduction of adenosine triphosphate (ATP) and balances intracellular acidosis and electrolyte levels. Consequently, the cell is prevented from calcium overload and free oxygen radicals; and neutrophil infiltration is inhibited (8-10).

According to these effects of TMZ, it can be suggested that TMZ may be used in other neurologic disorders and peripheral nerve injuries $(11,12)$. Although this hypothesis was suggested in the previous publications, there was no report of the effect of TMZ on primer repair of peripheral nerve injuries.

The aim of this study was to investigate the effects of TMZ on nerve regeneration in a rat sciatic nerve injury model. 


\section{Methods}

Animals

In this study 30 male Sprague Dawley albino mature rats, weighing 200-220 g, were used. Animals were fed ad libitum and housed in pairs in steel cages having a temperature-controlled environment $\left(22 \pm 2{ }^{\circ} \mathrm{C}\right)$ with 12-h light/dark cycles. The experimental procedures were approved by the Committee for Animal Research. All animal studies are strictly conformed to the animal experiment guidelines of the Committee for Human Care.

\section{Experimental protocol}

30 male Sprague Dawley rats were included in to the study. 20 rats were taken as experimental groups and surgical sciatic nerves disection and repair operation was performed on them. 10 rats were taken as normal control group $(\mathrm{n}=10)$ and no surgical operation or drug treatment was performed.

Experimental groups (20 rats) were divided into 2 groups. Surgery+Water group $(\mathrm{n}=10)$ rats were assigned to a placebo group and were given $1 \mathrm{ml}$ per day of tap water by oral gavage. Surgery+TMZ group $(\mathrm{n}=10)$ rats were given $5 \mathrm{mg} / \mathrm{kg} /$ day trimetazidine (Vastarel (R), $20 \mathrm{mg}$ ) and the drug was dissolved in $1 \mathrm{ml}$ of tap water and given by oral gavage. All medications were given for 12 weeks.

At the end of 12 weeks, motor function test was performed. After motor function test, electromyography (EMG) recordings were done. Finally, blood samples were taken by tail vein puncture for biochemical analysis and than the animals were euthanized and sciatic nerve samples were taken for immunohistochemistry analysis.

\section{Surgical procedure}

Under the induction of general anesthesia $(75 \mathrm{mg} / \mathrm{kg}$ ketamin and $10 \mathrm{~g} / \mathrm{kg}$ xylazine, administered by intraperitoneal injection), rats were fixed to the operating table in prone position. Both sciatic nerves were exposed from $1 \mathrm{~cm}$ distal of the sciatic notch to $1 \mathrm{~cm}$ distal to trifurcation of the nerve using aseptic technique. $3-3.5 \mathrm{~cm}$ long nerve segments above the trifurcation were dissected carefully to isolate the sciatic nerve from surrounding soft tissue. Then the nerves were transected by the micro scissors at a level of $1.5 \mathrm{~cm}$ above the trifurcation (i.e., starting point of tibial nerve, common peroneal nerve, and caudal sural cutaneous nerve).

Nerves were repaired with three epineural sutures (Ethilon ${ }^{\circledR}$ 9-0, Ethicon) by the same surgeon.

The wound was closed with a 3-0 Vicryl ${ }^{\circledR}$ and the rats were allowed to recover. After the recovery from anesthesia, rats were returned to their cages and allowed freely to get food and water.

\section{Measurement of tissue lipid peroxidation (MDA)}

Lipid peroxidation was determined in tissue samples by measuring malondialdehyde (MDA) levels as thiobarbituric acid reactive substances (13). Briefly, trichloroacetic acid and TBARS reagent were added to the tissue samples, then mixed and incubated at $100{ }^{\circ} \mathrm{C}$ for 60 minutes. After cooling on ice, the samples were centrifuged at $3000 \mathrm{rpm}$ for $20 \mathrm{~min}$ and the absorbance of the supernatant was read at $535 \mathrm{~nm}$. MDA levels were calculated from the standard calibration curve using tetraethoxypropane and expressed as $\mathrm{nmol} / \mu \mathrm{gr}$ protein.

\section{Electrophysiological recordings}

Rats were anesthetized by combination of ketamine hydrochloride at a dose of $80 \mathrm{mg} / \mathrm{kg}$ (Alfamine, Alfasan International B.V. Holland) and $10 \mathrm{mg} / \mathrm{kg}$ of xylazine hydrochloride (Alfazyne, Alfasan International B.V. Holland).

Electrophysiological recordings (EMG studies) were performed in all groups at the end of the study. EMG was obtained three times from the right sciatic nerve stimulated supramaximally (intensity $10 \mathrm{~V}$, duration $0.05 \mathrm{~ms}$, frequency $1 \mathrm{~Hz}$, in the range of $0.5-5000 \mathrm{~Hz}, 40 \mathrm{kHz} / \mathrm{s}$ with a sampling rate) by a bipolar subcutaneous needle stimulation electrode (BIOPAC Systems, Inc, Santa Barbara, CA) from the sciatic notch. CMAPs were recorded from 2-3 interosseous muscles by unipolar platinum electrodes. Data were evaluated using Biopac Student Lab Pro version 3.6.7 software (BIOPAC Systems, Inc) with distal latency and amplitude of CMAP as the parameters. During the EMG recordings, rectal temperatures of the rats were monitored by a rectal probe (HP Viridia 24-C; Hewlett-Packard Company, Palo Alto, CA) and the temperature of each rat was kept at approximately $36-37^{\circ} \mathrm{C}$ by heating pad. All experiments were performed between 10:00 a.m. and 14:00 p.m.

\section{Assessment of motor function}

The motor performances of the rats were evaluated by inclined-plate test according to the method described by Rivlin and

Tab. 1. Comparison of EMG CMAP latency (ms), EMG CMAP amplitude $(\mathrm{mV})$, Inclaned plane score between groups.

\begin{tabular}{|c|c|c|c|}
\hline & $\begin{array}{c}\text { Normal } \\
\text { control }\end{array}$ & $\begin{array}{c}\text { Surgery+ } \\
\text { Water group }\end{array}$ & $\begin{array}{c}\text { Surgery+ } \\
\text { TMZ group }\end{array}$ \\
\hline EMG CMAP latency (ms) & $2.34 \pm 0.11$ & $3.67 \pm 0.18^{*}$ & $3.1 \pm 0.04 \#$ \\
\hline EMG CMAP amplitude (mV) & $12.83 \pm 0.9$ & $1.89 \pm 0.35^{*}$ & $5.69 \pm 0.25 \# \#$ \\
\hline Inclaned plane score $\left(^{\circ}\right)$ & $87.6 \pm 1.3$ & $34.4 \pm 2.11 *$ & $72.8 \pm 2.86 \# \#$ \\
\hline \multicolumn{4}{|c|}{$\begin{array}{l}* \mathrm{p}<0.0001, \text { surgery+water group compared with Normal control, } \# \# \mathrm{p}<0.0001 \text {, } \\
\text { surgery+TMZ group compared with Surgery+Water group, \#p }<0.05 \text {, surgery+TMZ } \\
\text { group compared with Surgery+Water group, EMG: Electromyography, CMAP: Com- } \\
\text { pound Muscle Action Potential, TMZ: Trimetazidine }\end{array}$} \\
\hline
\end{tabular}
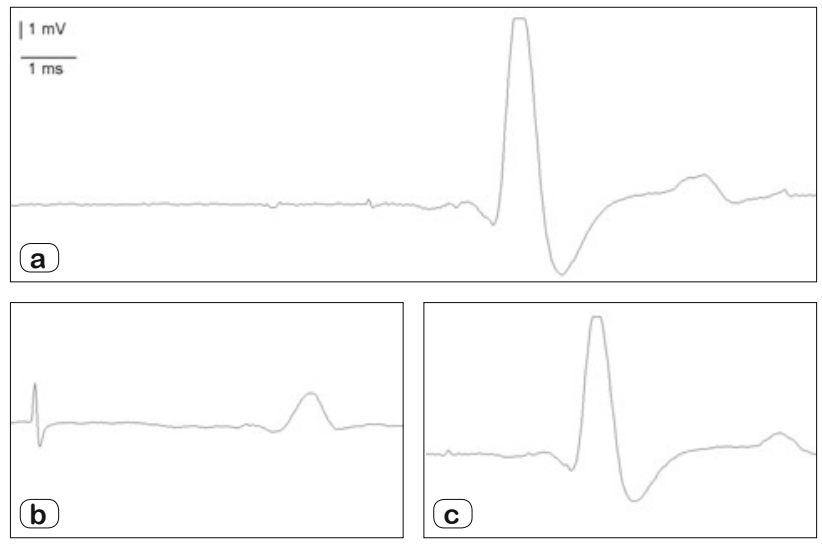

Fig. 1. EMG Record. a) Normal group, b) Surgery+Water group, c) Surgery+TMZ group. 
Tator. Briefly, the rat was placed oblique to the long axis of an inclined plate. The initial angle of the inclined plate was 10 degrees. The incline angle slowly increased and the maximum angle of the plate on which the rat preserved its position for $5 \mathrm{~s}$ without falling was recorded as motor score. The inclined plate angle was measured three times in each rat to find an average value.
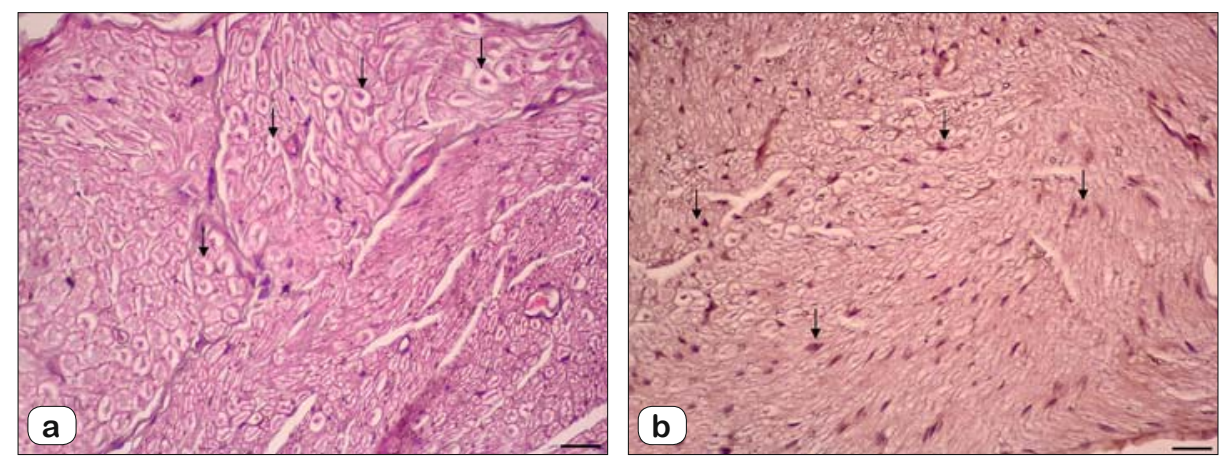

Histology and quantitative immunohistochemistry

Rats were perfused intracardiacly with $4 \%$ formaldehyde for histology and quantitative immunohistochemistry. Briefly, sciatic nerves were embedded in paraffin, sectioned at $5 \mu \mathrm{m}$ thickness via microtome (Leica RM 2145) and stained with hematoxylin- eo$\sin (\mathrm{H} \& \mathrm{E})$. Axons were detected with $H \& E$ staining. The thickness of the sciatic epineurium nerve was measured, and the stained tissue sections were then examined with an Olympus C-5050 digital camera mounted on an Olympus BX51 microscope (Tokyo, Japan). In each group, the Image-Pro Express 4.5 (Media Cybernetics, Inc., Rockville, MD, USA) program was used to measure the total axon number, the thicknesses of the perineural layers in the middle regions of the grafts and the level of fibrosis cov-
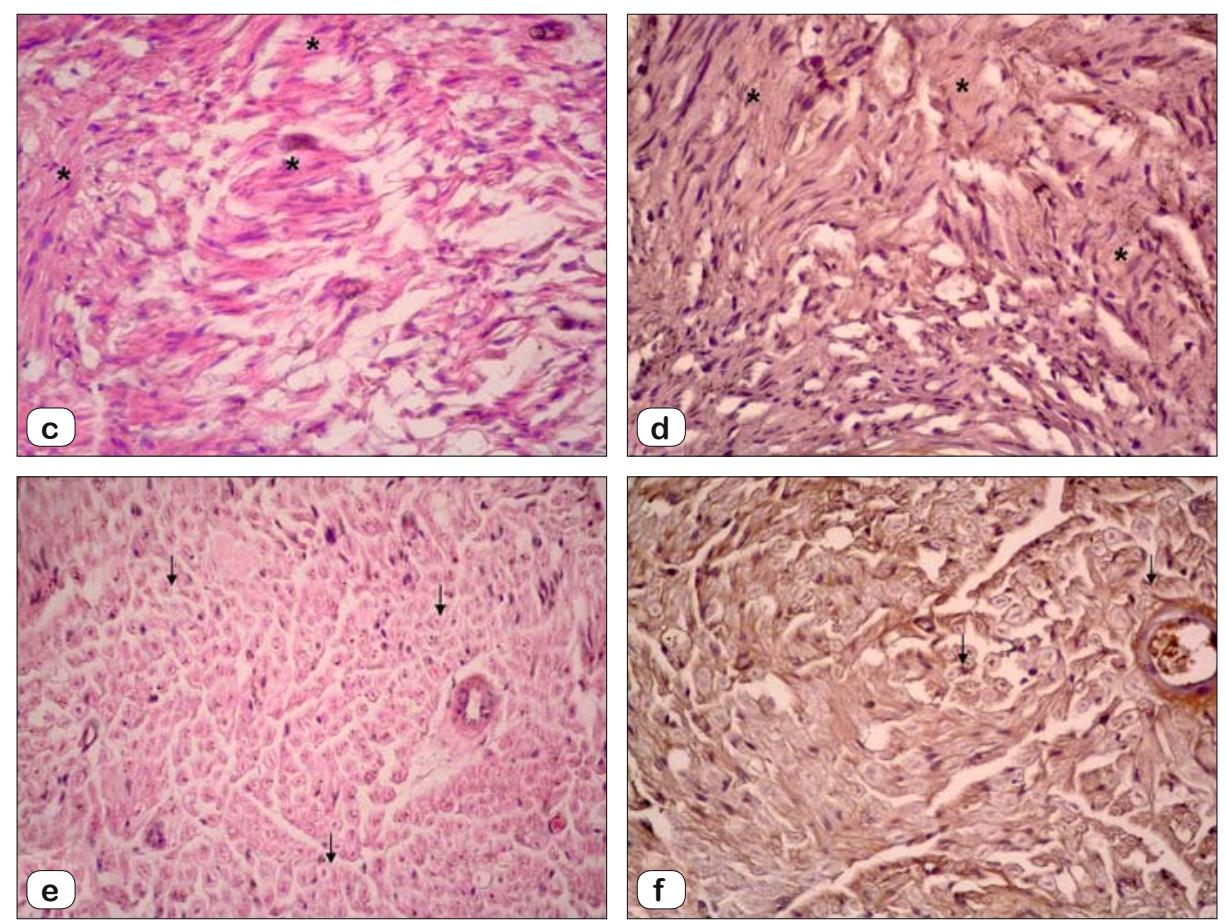

Fig. 2. X 20 Magnification. Hematoxylin \& Eosine and NGF immunexpression. a-b) Normal Group: arrow shows NGF expression in Schwann cell, c-d) Surgery+Water group, *fibrosis, e-f) Surgery+TMZ group, arrow shows NGF expression in Schwann cell. ering these layers in the histological specimens and then analyzed statistically.

For immunohistochemical examination, sections were incubated with $\mathrm{H}_{2} \mathrm{O}_{2}(10 \%)$ for 30 min to eliminate endogenous peroxidase activity and then blocked with normal goat serum (Invitrogen) for 1 hour at room temperature. Subsequently, sections were incubated with primary antibodies (Santacruz Biotechnology; 1/100) against nerve growth factor (NGF) for $24 \mathrm{~h}$ at $4{ }^{\circ} \mathrm{C}$. Antibody detection was carried out with the Histostain-Plus Bulk kit (Invitrogen) against rabbit IgG and 3,3' diaminobenzidine (DAB) was used to visualize the final product. All sections were washed in PBS, examined under Olympus BX51 microscope and photographed with Olympus C-5050 digital camera. All groups and six sections from each animal were used for quantitative immunohistochemistry. Two blinded observers counted the total immune- positive Schwann cells and the number of axons under a light microscope at X 10 and X 20 magnification. Data were expressed as mean SD, SEM.

\section{Statistical analysis}

Statistical analysis was carried out with the IBM, SPSS version 20 . The data is expressed as mean $\pm \mathrm{SD}$ for each group. For multiple comparisons, one-way ANOVA was used. A probability value of $p<0.05$ was considered statistically significant.

\section{Results}

\section{Inclined plane test/motor function results}

We evaluated motor performance in sciatic nerve injury model using an inclined plane test at the end of the study. Compared with the Normal control group, Surgery+Water group had decreased performance of this task. The mean climbing angles in group of Surgery+Water were significantly poorer than that of the Normal control group $\left(87.6 \pm 1.3^{\circ}\right)$. The rats in Surgery+TMZ group were able to climb higher degrees in the 


\section{$777-782$}

inclined plane. The mean climbing angles were $72.8 \pm 2.86^{\circ}$ in Surgery+TMZ group while the Surgery+Water group showed $34.4 \pm 2.11^{\circ}$ (Tab. 1 ).

\section{Evaluation of electrophysiological recordings}

In the Surgery+Water group, the amplitudes of CMAP decreased significantly as compared to the control group. The latency of CMAP was significantly prolonged when compared to the control group.

However, the amplitudes of CMAP increased significantly in the Surgery+TMZ group when compared with the group that have been given Surgery+Water. The latency of CMAP was significantly shortened in the Surgery+TMZ group as compared to the Surgery+Water group (Fig. 1 and Tab. 1).

\section{Histological changes of the sciatic nerve}

At the end of the study, following Wallerian degeneration of the sciatic nerves, the number of axons was decreased in Surgery+Water group, all of which were more prominent in the Surgery+Water group than in Surgery+TMZ group. There was a significant difference in the number of axons between the Surgery+TMZ group and Surgery+Water groups $(\mathrm{p}<0.0001)$ (Tab. 2 ). Moreover, fibrosis score was reduced in the Surgery $+\mathrm{TMZ}$ group compared to the Surgery+Water group (Fig. 2).

\section{Fibrosis score and NGF immunoexpression in the sciatic nerve}

The fibrosis scores in the sciatic nerve tissues of the Surgery+Water group were significantly increased when compared with the Normal control group $(\mathrm{p}<0.0001)$ (Fig. 2, Tab. $2)$. Similarly, the fibrosis score was increased minimally in the Surgery+TMZ group compared with the Normal control group $(\mathrm{p}<0.0001)$. It was significantly decreased in the Surgery+TMZ group as compared to the Surgery+Water group $(\mathrm{p}<0.0001)$.

NGF immunoexpression in the Schwann cell of the Surgery+Water group was significantly decreased compared with the Normal control group $(\mathrm{p}<0.0001)$. NGF immunoexpression in

Tab. 2. Comparison of NGF immunexpression on Schwann cell, Total axon number, Fibrosis score between groups.

\begin{tabular}{lccc}
\hline & $\begin{array}{c}\text { Normal } \\
\text { control }\end{array}$ & $\begin{array}{c}\text { Surgery+ } \\
\text { Water group }\end{array}$ & $\begin{array}{c}\text { Surgery+ } \\
\text { TMZ group }\end{array}$ \\
\hline $\begin{array}{l}\text { NGF immunexpression } \\
\text { on Schwann cell }(\%)\end{array}$ & $38.7 \pm 7.72$ & $5.2 \pm 1.8^{*}$ & $16.4 \pm 5.1 \#$ \\
\hline Total axon number & $1210.78 \pm 56.3$ & $345.1 \pm 41.6^{*}$ & $985.5 \pm 43.25 \#$ \\
\hline Fibrosis score (\%) & $1.6 \pm 0.2$ & $78.5 \pm 6.4^{*}$ & $13.4 \pm 3.75 \#$ \\
\hline $\begin{array}{l}* \\
\text { p }<0.0001, \text { surgery+water } \\
\text { surgery+TMZ group compared }\end{array}$ & with Normal control, \#p<0.0001, \\
Factor
\end{tabular}

Tab. 3. Comparison of MDA quantities between groups.

\begin{tabular}{lccc}
\hline & $\begin{array}{c}\text { Normal } \\
\text { control }\end{array}$ & $\begin{array}{c}\text { Surgery+ } \\
\text { Water group }\end{array}$ & $\begin{array}{c}\text { Surgery+ } \\
\text { TMZ group }\end{array}$ \\
\hline $\mathrm{MDA}(\mathrm{nmol} / \mu \mathrm{gr})$ & $114.1 \pm 4.98$ & $203.8 \pm 21.03^{*}$ & $156.8 \pm 12.5 \#$ \\
\hline
\end{tabular}

$* \mathrm{p}<0.0001$, surgery+water group compared with Normal control, $\# \mathrm{p}<0.001$, surgery+TMZ group compared with Surgery+Water group, MDA: Malondialdehyde, TMZ: Trimetazidine the Schwann cell was significantly increased in the Surgery+TMZ group compared with the Surgery+Water group $(\mathrm{p}<0.0001)$.

\section{LPO level}

Comparisons of the groups' MDA levels are presented in Table 3. The level of MDA was increased in the Surgery+Water group when compared to the normal control group $(\mathrm{p}<0.0001)$. In Surgery+TMZ group, Trimetazidine treatment significantly reduced the MDA levels compared to the Surgery+Water group $(\mathrm{p}<0.001)($ Tab. 3).

\section{Discussion}

In our experimental study, we performed end-to-end primary repair to traumatically interrupted sciatic nerves on rats and showed TMZ's regenerative effects.

TMZ is an anti-anginal cardioprotective agent mostly used in the treatment of coronary artery disease (14). In previous studies, effectiveness of TMZ treatment has been shown in oxidative stress related traumas $(15,16)$. TMZ's neural effects have been proven clinically in semicircular canals (11); however its effects on peripheral nervous system are still being investigating in several studies. We do not have any pharmacological treatment to administer after nerve injury. However, potential agents like various hormones, peptides and growth factors are suggested because of their predicted neuro-regenerative effects (1).

It has been proven that micro-environment conditions, cellular and molecular activation is really important for nerve healing process (17). After nerve injury, secondary to impairment of micro-environment via ischemia-reperfusion damage, neutrophil and macrophage activation and increased mitochondrial oxidative stress; nerve healing process is adversely affected (12). Superoxyde dismutase (SOD) and catalase (CAT) are cellular anti-oxidants that prevent cells from oxidative stress. Lipid peroxidation (LPO) is an important marker of oxidative stress caused by free oxygen radicals. Malone dialdehyde(MDA) is a marker of LPO (18). An increase in MDA levels means an increase in oxidative stress and impairment of micro-environment. In our study, we measured MDA levels to evaluate TMZ's anti-oxidant effect on nerve healing and detected significantly low MDA levels in Surgery+TMZ grop when compared to Surgery+Water group.

Electrophysiological studies are most referenced evaluation methods in peripheral nerve injury models (19). In compound muscle action potential (CMAP) curves that are obtained via supramaximal stimulation, distance between positive and negative peaks (p-p distance) refers to amplitude (20). Amplitude gives us information about responsive motor fibers and innervated motor units magnitude. By improvement of axonal regeneration and remyelinization; recorded responses become more synchronous and generate higher amplitudes. An increase in the number of motor units which are innervated by regenerated axons causes an inrease in CMAP amplitudes (21). In our study, we detected higher amplitudes in Surgery+TMZ group when compared to Surgery+Water group. With these results we showed that TMZ has positive effects on nerve regeneration and remyelinization. 
Latency value is the time between stimulation and beginnings of muscle contraction potential. Latency value gives us information about myelinization. In sciatic nerve studies on rats, electrophysiological records should be taken from interosseous muscles. Because of gastrocnemius muscles proximity to large muscle groups, records taken from these muscles could be misleading (21). In our study, we detected longer latency time, which was evaluated in the plan of interosseous muscles, in Surgery+Water group.

Taken together, these data indicate that administration of TMZ promotes functional recovery and enhances nerve regeneration after sciatic nerve damage in the rat. In the present study, we observed that the improvement in functional recovery was accompanied by significant increases in axon counts in the nerve regeneration site. There is an increasing evidence that growth factors may act at multiple levels in the regenerative response of nerve healing (22-25). One such factor affecting multiple cell processes is NGF. NGF is a member of a family known as neurotrophins that function as signaling molecules. These cytokines are important for the growth, maintenance, and survival of neural cells $(25,26)$. NGF is one of the six growth factors, and triggered tyrosine kinase receptors play a role in the survival and differentiation of neurons in the central nervous system (27). The percentage of NGF immunoexpression is related to neuronal cell loss in Schwann cells. In our study, the percentage of NGF immunoexpression was decreased in the Surgery+Water group and was ameliorated with TMZ treatment. We showed that TMZ treatment may also decrease the fibrosis score and increase the NGF immunoexpression. Also, in literature there is no study that would have shown TMZ's effects on NGF immunoexpression. By the way, we think that our study would pave the way for further neuroprotective studies.

The present study demonstrated that oxytocin enhances peripheral nerve regeneration in a rat sciatic damage model. This positive impact can be attributed to the benefits of oxytocin in stimulating the nerve growth factors that is obviously presented in the literature such as NGF which has positive effects in nerve tissue healing $(22,24)$. Besides, histomorphometric examination of sciatic nerve showed a significant reduction in fibrosis in Surgery+TMZ group. The assessment of oxidative status of study groups revealed that TMZ was able to decrease plasma lipid peroxides (MDA) in Surgery $+\mathrm{TMZ}$ group. In addition to biochemical and histological findings, our results showed that TMZ could successfully improve the electrophysiological parameters including CMAP duration, amplitude and latency in Surgery+TMZ group. Overall, these results suggest a direct evidence of cytoprotective potential of TMZ against oxidative stress in a rat sciatic damage model.

Altough nerve healing is evaluated histologically, biochemically and electrophysiologically; functional results are more important. In our study, we used Rivlin and Tator's (1977) tilt table test to evaluate motor function (28). In Surgery+Water group, rats show their motor functions actively on $34.4 \pm 2.1^{\circ}$; however in Surgery+TMZ group, rats show their motor functions actively on $72.8 \pm 2.86^{\circ}$. Despite we could not show significant effect of $\mathrm{TMZ}$ on functional results, a single test is not sufficient to evaluate functional amelioration. For a cantitative test, a test combination which investigates certain components of normal and improved motor function is required (29). One of our study's downward bias is inadequate motor function analysis. For this, further experimental studies are required.

In a study of Seraslan et al. , they proved TMZ treatments effectiveness on sciatic nerve's crush injury model (30). In another study performed by Atilgan et al. , cavernous nerve damage was done by clamp and nerve integrity was preserved (31). The difference of our study from these studies is our nerve injury model and treatment procedure. We created our nerve injury model via a penetrating cut trauma, performed end-to-end primary repair and then TMZ treatment. We showed effectiveness on TMZ treatment in this situation. When compared with the previous studies in literature, our study will pioneer further studies.

\section{Conclusion}

We do not have any pharmacological treatment to be administered after nerve injury. However, potential agents like various hormones, peptides and growth factors are suggested because of their predicted neuro-regenerative effects. In conclusion, we demonstrated the superiority of TMZ on nerve healing in our experimental study which was evaluated with comparative groups.

\section{References}

1. Faroni A, Mobasseri SA, Kingham PJ, Reid AJ. Peripheral nerve regeneration: experimental strategies and future perspectives. Adv Drug Deliv Rev 2015; 82: 160-167.

2. Kline DG, Kim D, Midha R, Harsh C, Tiel R. Management and results of sciatic nerve injuries: a 24-year experience. J Neurosurg 1998; 89: 13-23.

3. Lundborg G. Enhancing posttraumatic nerve regeneration. J Periph Nerv Syst 2002; 7: 139-140.

4. Huang W, Begum R, Barber T, Ibba V, Tee NC, Hussain M, et al. Regenerative potential of silk conduits in repair of peripheral nerve injury in adult rats. Biomaterials 2012; 33: 59-71.

5. Bagdatoglu C, Saray A, Surucu HS, Ozturk H and Tamer L. Effect of trapidil in ischemia/reperfusion injury of peripheral nerves. Neurosurgery 2002; 51 (1): 212-220.

6. Fairbairn NG, Meppelink AM, Ng-Glazier J, Randolph MA, Winograd JM. Augmenting peripheral nerve regeneration using stem cells: A review of current opinion. World J Stem Cells 2015; 7 : 11.

7. Faure JP, Baumert H, Han Z, Goujon JM, Favreau F, Dutheil D. Evidence for a protective role of trimetazidine during cold ischemia: targeting inflammation and nephron mass. Biochem Pharmacol 2003; 66 (2): 241-2250.

8. López N, Varo N, Díez J, Fortuño MA. Loss of myocardial LIF receptor in experimental heart failure reduces cardiotrophin-1 cytoprotection. A role for neurohumoral agonists? Cardiovasc Res 2007; 75 (5): 36-545.

9. Blardi P, de Lalla A, Volpi L, Auteri A, Di Perri T. Increase of adenosine plasma levels after oral trimetazidine: a pharmacological preconditioning? Pharmacol Res 2002; 45: 69-72.

10. Ozden S, Kildaci B, Muftuoglu S, Cakar N, Yildirim C. Effect of trimetazidine on retinal ischemia/reperfusion injury in rats. Ophthalmologica 2001; 215: 309-317. 
$777-782$

11. Coyas A. The efficacy of trimetazidine in cochleovestibular disorders of ischemic origin. A crossover control versus placebo trial. Ann Otolaryngol Chir Cervicofac 1990; 107: 82-87.

12. Coban YK, Ciralik H, Kurulas EB. Ischemic preconditioning reduces the severity of ischemiareperfusion injury of peripheral nerve in rats. J Brachial Plex Peripher Nerve Inj 2006; 1: 2.

13. Demougeot C, Marie C, Beley A. Importance of iron location in iron-induced hydroxyl radical production by brain slices. Life Sci 2000: 67; 399-410.

14. Iskesen I, Saribulbul O, Cerrahoglu M, Var A, Nazli Y, Sirin H. Trimetazidine reduces oxidative stress in cardiac Surgery Circ J 2006; 70: 1169-1173.

15. Tetik C, Ozden A, Calli $\mathbf{N}$ et al. Cytoprotective effect of trimetazidine on 60 minutes of intestinal ischemia-reperfusion injury in rats. Transpl Int 1999; 12 (2): 108-112.

16. Mohand-Said S, Jacquet A, Lucien A, Espinasse-Berrod MA, De Silva MFC, Sahel J. Protective effect of trimetazidine in a model of ischemia-reperfusion in the rat retina. Ophthalmic Res 2002; 34: 300-305.

17. Rotshenker S. Wallerian degeneration: the innate-immune response to traumatic nerve injury. J Neuroinflammation 2011; 8: 109.

18. Koracevic D, Koracevic G, Djordjevic V, Andrejevic S, Cosic V. Method for the measurement of antioxidant activity in human fluids. J Clin Pathol 2001; 54: 356-361.

19. Panseri S, Cunha C, Lowery J et al. Electrospun micro-and nanofiber tubes for functional nervous regeneration in sciatic nerve transections. BMC Biotechnol 2008; 8: 39.

20. Chung MS, Baek GH, Oh JH, Lee YH, Bin SW, Gong HS. The effect of muscle length and excursion on muscle contracture after tendon injury: A study in rabbit soleus muscles. Injury 2007; 38: 1139-1145.

21. Wolthers M, Moldovan M, Binderup T, Schmalbruch H, Krarup C. Comparative electrophysiological, functional and histological studies of nerve lesions in rats. Microsurgery 2005; 25: 508-519.
22. Gao J, Ma S, Ji Y, Wang JE, Li J. Sciatic nerve regeneration in rats stimulated by fibrin glue containing nerve growth factor: an experimental study. Injury 2008; 39 (12): 1414-1420.

23. Mohammadi R, Esmaeil-Sani Z, Amini K. Effect of local administration of insulin-like growth factor I combined with inside-out artery graft on peripheral nerve regeneration. Injury 2013; 44 (10): 1295-1301.

24. Johnson EO, Charchanti A, Soucacos PN. Nerve repair: experimental and clinical evaluation of neurotrophic factors in peripheral nerve regeneration. Injury 2008; 39 (3): 37-42.

25. Boyd JG, Gordon T. Neurotrophic factors and their receptors in axonal regeneration and functional recovery after peripheral nerve injury. Mol Neurobiol 2003; 27 (3): 277-324.

26. Boyd JG, Gordon T. The effect of nerve growth factors is known to be dosedependent. A dose-dependent facilitation and inhibition of peripheral nerve regeneration by brain-derived neurotrophic factor. Eur J Neurosci 2002; 15: 613-626.

27. Dai CF, Steyger PS, Wang ZM, Vass Z, Nuttall AL. Expression of Trk A receptors in the mammalian inner ear. Hearing Res 2004; 187: 1-11.

28. Rivlin AS, Tator CH. Objective clinical assessment of motor function after experimental spinal cord injury in the rat. J Neurosurg 1977; 47: 577-581.

29. Kunkel-Bagden E, Dai HN, Bregman BS. Methods to assess the development and recovery of locomotor function after spinal cord injury in rats. Exp Neurol 1993; 119: 153-164.

30. Serarslan Y, Bal R, Altug ME et al. Effects of trimetazidine on crush injury of the sciatic nerve in rats: a biochemical and stereological study. Brain Res 2009; 1247: 11-20.

31. Atilgan D, Parlaktas BS, Uluocak $\mathbf{N}$ et al. The effects of trimetazidine and sildenafil on bilateral cavernosal nerve injury induced oxidative damage and cavernosal fibrosis in rats. Sci World J 2014; 2014.

Received April 4, 2019. Accepted May 23, 2019. 